MEASURING

CULTURE 



\section{MEASURING CULTURE}

JOHN W. MOHR

CHRISTOPHER A. BAIL

MARGARET FRYE

JENNIFER C. LENA

OMAR LIZARDO

TERENCE E. MCDONNELL

ANN MISCHE

IDDO TAVORY

FREDERICK F. WHERRY 


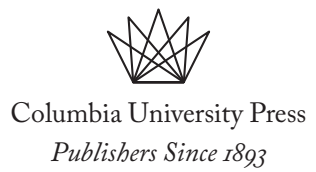

New York Chichester, West Sussex cup.columbia.edu

Copyright (C) 2020 John W. Mohr, Christopher A. Bail, Margaret Frye, Jennifer C. Lena, Omar Lizardo,

Terence E. McDonnell, Ann Mische, Iddo Tavory, and Frederick F. Wherry

All rights reserved

Library of Congress Cataloging-in-Publication Data

Names: Mohr, John, author.

Title: Measuring culture / John W. Mohr [and eight others].

Description: New York : Columbia University Press, 2020. |

Includes bibliographical references and index.

Identifiers: LCCN 2019052336 (print) | LCCN 2019052337 (ebook) |

ISBN 978023II80283 (hardback) | ISBN 978023II80290

(trade paperback) | ISBN 9780231542586 (ebook)

Subjects: LCSH: Culture. | Culture-Research-Methodology.

Classification: LCC HM623.M64 2020 (print) |

LCC HM623 (ebook) | DDC 306 - dc23

LC record available at https://lccn.loc.gov/2019052336

LC ebook record available at https://lccn.loc.gov/2019052337

Columbia University Press books are printed on permanent and durable acid-free paper.

Printed in the United States of America 